\title{
Educação Superior no Século XXI e a Reforma Universitária Brasileira
}

Arthur Roquete de Macedo

Ligia Maria Vettorato Trevisan

Péricles Trevisan

Caio Sperandeo de Macedo

\section{RESUMO}

Tomando como referência a evolução e as características do sistema brasileiro de educação superior discute-se neste artigo os fundamentos de uma efetiva reforma da educação superior. Procura-se mostrar que a adequação desse sistema para o enfrentamento dos desafios da sociedade do conhecimento, em um país como o Brasil, deve necessariamente resolver três questões: a modernização do sistema, o efetivo aprimoramento da qualidade da educação brasileira em todos os níveis, graus e modalidades e a democratização do ensino promovendo a inclusão social.

Palavras-chave: Educação superior brasileira. Reforma universitária. Reforma do ensino superior. Educação superior.
ABSTRACT

Higher

Arthur Roquete de Macedo

Membro do Conselho Nacional

de Educação e da Academia

Brasileira de Educação

Ex-Reitor da Universidade

Estadual Paulista (UNESP)

a.roquetedemacedo@terra.com.br

Ligia Maria Vettorato Trevisan

Professora Livre Docente da

Universidade Estadual Paulista

Consultora Educacional, Qualitas Consultoria

lmtrevisan@terra.com.br

\section{Péricles Trevisan}

Professor Adjunto da Universidade Federal de São Carlos

Consultor Educacional, Qualitas Consultoria

péricles.trevisan@terra.com.br

Caio Sperandeo de Macedo

Advogado; Mestrando em Direito

Constitucional, PUC-SP

Consultor em Direito Educacional caio.csm@ig.com.br
Education: the XXI century and the brazilian university reform

This paper aims to present the essential basis for an effective higher education reform. The strategies chosen by the authors to develop and to construct their proposals are based on studies of evolution and special features of the Brazilian Higher Education System. By analyzing this special and highly complex system the authors could conclude that in order to fit the challenges which emerge from the knowledge society the higher education system reform 
adjusted to a country like Brazil has to be reorganized in order to present solutions to three main questions: the system modernization, the improvement of the quality of the whole brazilian education system and the promotion of social inclusion through the access democratization.

Keywords: Brazilian higher education. University reform. Higher education reform. Brazilian system of higher education.

\section{RESUMEN}

\section{Educación Superior en el Siglo XXI y la Reforma Universitaria Brasileña}

Tomando como referencia la evolución y las características del sistema brasileño de educación superior, en este artículo se discuten los fundamentos de una efectiva reforma de la educación superior. Se intenta mostrar que la adecuación de este sistema para el enfrentamiento de los desafíos de la sociedad del conocimiento, en un país como Brasil, se deben necesariamente resolver tres cuestiones la modernización del sistema, la efectiva mejora de la calidad de la educación brasileña a todos los niveles, grados y modalidades, y, la democratización de la enseñanza promoviendo la inclusión social.

Palabras-clave: Educación Superior Brasileña - Reforma Universitaria - Reforma de la Enseñanza Superior - EducaciónSuperior.

\section{Introdução}

modelo de formação universitária prevalecente na imensa maioria dos países ocidentais durante o século XX está se esgotando. $E$ as razões para isso são muitas. $O$ ritmo e a intensidade das mudanças no universo do trabalho, a evolução do conhecimento em todas as áreas, a transformação da ciência e do saber em força produtiva, o surgimento contínuo de novas especialidades e a demanda permanente de novos tipos de profissionais, marcadas pela flexibilidade e pela interdisciplinaridade em níveis até há pouco inimagináveis. É uma questão que afeta o sistema de educação superior como um todo e que deve marcar e orientar qualquer projeto de reforma de um sistema de educação superior. Entretanto, ela é unilateral uma vez que aborda a universidade de um único ângulo, que é aquele que corresponde ao processo de formação e a seus resultados, ou seja, ao profissional que está sendo formado. Em conseqüência, há que buscar outros referenciais que possam contribuir para a configuração mais precisa do objeto da reforma: a instituição de educação superior.

No Brasil do Séc. XXI essa é uma tarefa essencial. Primeiro pela dimensão, complexidade e juventude do sistema nacional de educação superior. Segundo, pela sua heterogeneidade, que deriva não apenas das acentuadas diversidades e desigualdades regionais brasileiras mas também das características dos dois diferentes momentos de expansão do sistema nacional de educação superior.

Este cenário gera: a necessidade de um novo modelo de Universidade, de diversificação das Instituições de Educação Superior - IES -, e de novas modalidades de formação universitária.

A reforma universitária implantada no Brasil em 1968 foi planejada pelo segundo governo militar e embutia um projeto de nação alimentado pelo veio da grandeza e pela luta contra o socialismo e o comunismo. $O$ projeto de nação não alcançou o 
resultado desejado, mas a reforma universitária, essa sim, aconteceu. Extensa e profunda. De alto impacto, dada a forte repressão política a que foi submetida a instituição universitária no período de sua implantação e a natureza transformadora das medidas por ela introduzidas.

É inegável que, apesar de sua natureza autoritária, antidemocrática e centralizadora, a reforma implementou, em meio a medidas de discutível mérito, algumas inovações importantes. Assim, ao lado da reformulação da natureza dos exames vestibulares, que ao eliminar a figura do excedente apenas encobriu a dolorosa marca da exclusão característica das carreiras de alto prestígio social, houve a extinção da cátedra, o estabelecimento de uma carreira universitária aberta e baseada no mérito acadêmico, a instituição do departamento como unidade mínima de ensino e pesquisa, e a criação dos colegiados de curso.

A Lei de Diretrizes e Bases de 1968 (BRASIL, 1968), no art. $2^{\circ}$, retomando uma concepção da reforma Francisco Campos de $1931^{1}$, abandonada pela legislação de $1961^{2}$, estabeleceu que o ensino superior, indissociável da pesquisa, seria ministrado em universidades e, apenas excepcionalmente, em estabelecimentos isolados, organizados como instituições de direito público ou privado. Com isso a reforma de 1968 privilegiou um modelo único de instituição de ensino superior no qual a pesquisa estava inserida no cotidiano acadêmico, e a extensão recebia uma função ainda pouco definida e de via única, restrita à transferência e resultados à sociedade e ao oferecimento, aos estudantes, de oportunidades de participação em programas de melhoria das condições de vida da comunidade. ${ }^{3}$

Suportado por um volume significativo de investimentos oficiais, o modelo de ensino superior subjacente à reforma de 1968 experimentou um grande crescimento durante a década de 1970. Com isso, a universidade consolidou-se como a principal fonte de desenvolvimento da atividade nacional de pesquisa, e ensaiou os primeiros passos do processo de constituição da extensão como atividade própria da instituição de ensino superior. Sem instrumentos próprios e, sobretudo, sem uma clara concepção a respeito da natureza e modalidades de articulação com a sociedade da qual faz parte, nesse primeiro período a universidade brasileira limitou sua atividade nessa área ou a responder a demandas pontuais do setor produtivo ou a implementar projetos de prestação de serviços no setor da saúde ou na formação e aperfeiçoamento de professores, aproveitando o estoque de recursos e de competências de que já dispunha nessas áreas.

Na medida mesma em que ocorriam esses avanços ficava cada vez mais clara a inadequação, para as condições e necessidades brasileiras, do modelo único de instituição de ensi-

\footnotetext{
1 Decreto $n^{\circ}$. 19.851, de 11 de abril de 1931. Dispõe que o ensino superior no Brasil obedecerá, de preferência, ao sistema universitário, podendo ainda ser ministrado em institutos isolados.

2 Lei $n^{\circ}$. 4.024, art. 67: "O ensino superior será ministrado em estabelecimentos, agrupados ou não em universidades, com a cooperação de institutos de pesquisa e centros de treinamento profissional".

${ }^{3}$ Lei n 5.540, art. 20, "As universidades e os estabelecimentos isolados de ensino superior estenderão à comunidade, sob forma de cursos e serviços especiais, as atividades de ensino e os resultados da pesquisa que lhes são inerentes"; art. 40. inciso a: "As instituições de ensino superior, por meio de suas atividades de extensão, proporcionarão aos corpos discentes oportunidades de participação em programas de melhoria das condições de vida da comunidade e no processo geral do desenvolvimento."
} 
no superior preconizado pela reforma de 1968. Ao longo dos anos 70 um vasto conjunto de normas e regulamentos, bem como de decisões do então Conselho Federal de Educação, viabilizaram a expansão do sistema nacional de educação superior pela criação de faculdades isoladas, evidência forte do fracasso do projeto de modelo único de organização.

Muitas instituições não universitárias, em sua imensa maioria privadas, foram criadas nesse período para atender a uma demanda crescente por educação superior que se verificara impossível de ser atendida pela universidade, pública ou privada, cuja expansão era limitada pelos altos custos acarretados pelo princípio da indissociabilidade ensino-pesquisa e pela dificuldade de manter em níveis adequados o investimento requerido pelo sistema público. Em conseqüência, a expansão do sistema no período é na verdade suportada pelas instituições não universitárias, predominantemente privadas. Em 1980 o país contava com 882 instituições de ensino superior: 65 universidades, 20 faculdades integradas e 797 estabelecimentos isolados. $\bigcirc$ total de matrículas, que em 1964 fora de 142.386, passou a 1.377.286 em 1980, 52,6\% das quais em instituições não universitárias.

A segunda fase de forte expansão do sistema de ensino superior ocorre a partir de 1995. De 1980 até esse ano o sistema experimentou um crescimento meramente vegetativo, $(1,36 \%)$ em termos de número de instituições, que passa de 882 para 994. Quanto às matrículas verifica-se que evolvem modestamente a uma taxa anual média da ordem de 1,65\%, passando de 1.377.286 para 1.759.7034 . A partir da segunda metade da década de 90 o crescimento do sistema experimenta uma vigorosa aceleração. Entre 1995 e 2000 o número de instituições cresce $32 \%$ e o total de matrículas 53,1\%; entre 2000 e 2005 o total de instituições de ensino superior chega a 2260, (incremento de 91,5\%), e entre 2000 e 2003 o número total de matrículas aumenta $42,3 \%$, chegando a cifra de 3.887.771.

Como facilmente se depreende, essa segunda e mais intensa fase de crescimento do sistema de ensino superior brasileiro ocorre na vigência da Constituição de 1988 (BRASIL, 1998), que consagrou os princípios da autonomia universitária e da indissociabilidade do ensino-pesquisa-extensão (art. 207), e fixou as normas básicas da participação do setor privado na oferta de ensino (art. 209), e da Lei $n^{\circ} .9 .394$ (BRASIL, 1996), que estabelece as diretrizes e bases da educação nacional.

Observando os princípios constitucionais a nova Lei de Diretrizes e Bases - LDB -promoveu, por seus dispositivos, uma ampla diversificação do sistema de ensino superior, pela previsão de novos tipos de instituição (universidades especializadas, institutos superiores de educação, centros universitários), instituiu novas modalidades de cursos e programas, e estabeleceu os fundamentos para a construção de um sistema nacional de avaliação da educação superior.

Com base nesse arcabouço legal, complementado por um conjunto de leis, decretos, portarias e resoluções, o sistema nacional de ensino superior experimentou não apenas uma vigorosa expansão, mas também uma profunda diversificação dos tipos de instituições que o compõem e uma alteração significativa de sua composição.

Em função do esgotamento da capacidade estatal de investimento o setor público do sistema teve sua participação continuamente reduzida: responsável por $42 \%$ das matrículas

4 Em contraste, a taxa média anual de evolução do número de matrículas no ensino superior, entre 1970 e 1980, é da ordem de 12,46\%. 
em meados dos anos 90 as instituições públicas respondem, nos anos iniciais do século XXI por menos de 30\% delas. Essa redução é ainda maior quando se analisa apenas o segmento federal de instituições públicas: sua participação no conjunto das matrículas passa de 20,8\% em 1995 para $14,6 \%$ em 2003.

Quanto à natureza e categoria administrativa das instituições observa-se, por um lado, a consolidação da participação das universidades privadas no conjunto do sistema, fixando uma tendência já presente ao longo dos anos 1980 e, por outro, a rápida expansão dos Centros Universitários criados a partir de 1997. Em 1999 o Instituto Nacional de Estudos Pedagógicos -INEP - registrava a existência de 39 Centros Universitários que respondiam por 6,8\% das matrículas. Em 2003 foram registradas 501.108 matrículas, $12,9 \%$ do total, em 81 Centros Universitários.

No que se refere às novas modalidades de cursos e programas o que se observa é a pequena envergadura das iniciativas. Os cursos seqüenciais, considerados inicialmente uma das inovações mais promissoras derivadas da LBD (BRASIL, 1996), apresentam um desempenho apenas razoável em razão sobretudo da legislação que regulamentou sua implantação e do repudio das corporações e entidades de classe aos estudantes por eles formados. Em 2000, 178 cursos exibiam 13.430 matrículas, $(0,5 \%$ do total); em 2003 contava-se 677 cursos com 48.833 matrículas, (1,2\% do total).

Por outro lado os Institutos Superiores de Educação e o Curso Normal Superior também não prosperaram em função da falta de apoio da academia e de rejeição do seu público alvo. A exceção foi a educação tecnológica que, em função de ter sido elevada a condição de curso superior de graduação e da autonomia concedida aos Centros de Educação Tecnológica ${ }^{5}$, tiveram um crescimento notável.

Apesar das possibilidades abertas pela nova LDB, e de toda legislação complementar regulamentadora, não é possível afirmar que o país foi capaz de implementar uma verdadeira reforma da educação superior na década de 90.

Não menos importante é a questão da qualidade do ensino superior nacional, tema de destacada projeção desde há muito. $\bigcirc$ Brasil tem desenvolvido metodologias importantes de avaliação, e é pioneiro na implantação da avaliação da qualidade na pós-graduação e na aplicação dos resultados dessa avaliação para recomendar e reconhecer programas de formação avançada. Inexistem dúvidas sobre a importância dessa avaliação, eis que, duradoura, contínua e sistematicamente aprimorada, transformou-se num poderoso subsídio para acompanhar a evolução do sistema nacional de formação de Mestres e Doutores. No ensino superior de graduação a avaliação da qualidade vem sendo realizada seja por agências oficiais, (credenciamento e recredenciamento de instituições, autorização, reconhecimento e renovação de reconhecimento de cursos, exames que avaliam a qualidade de formação dos egressos), seja pelas instituições educacionais, que têm desenvolvido projetos de auto-avaliação. Ainda assim, a avaliação precisa ser aprimorada, para vencer as dificuldades que decorrem da dimensão e da heterogeneidade do sistema nacional e da sua implantação recente em nosso meio.

5 Os decretos n’s 2.406 de 1997, 3.462 de 2000 e 3.741 de 2001 que garantiam autonomia aos Centros de Educação Tecnológica, públicos e privados, para a criação de cursos, foram revogados pelo Decreto n .5 .224 de 2004. Este decreto, ao transformar os Centros de Educação Tecnológica privados em Faculdades de Tecnologia restringiu a autonomia para a criação de cursos apenas aos Centros Federais. 
As considerações acima evidenciam o esgotamento do modelo implantado com a reforma universitária de 1968 e a necessidade de repensar nossa política educacional. Preparar as instituições de ensino superior para atender demandas da sociedade do conhecimento e de um mercado de trabalho globalizado, enfrentar o desafio de ampliar e democratizar o acesso à educação superior, definir e implementar novas políticas de financiamento de instituições, capazes de orientar a modernização de sua gestão, incentivar e avaliar a educação a distância, são problemas sérios cuja solução requer profunda revisão de objetivos, modelos, estruturas, mecanismos de funcionamento e de acompanhamento.

Em fins de 2004 o Ministério da Educação assumiu essa responsabilidade e apresentou à discussão pública um anteprojeto de reforma da educação superior que se revelou extremamente polêmico, haja vista o volume e a diversidade das manifestações críticas e das propostas de modificação a que deu origem.

Se é verdade que o MEC teve a coragem e a iniciativa de enfrentar o problema, não é menos verdade que não teve a sensibilidade para desencadear o processo no momento oportuno, com uma preparação prévia necessária para definir um projeto de reforma inovador, abrangente e que fosse ao encontro das necessidades da educação brasileira e das mais recentes tendências mundiais (MACEDO, 2005).

\section{Objetivos}

Este artigo não tem o escopo de criticar a proposta de reforma do Governo, mas o objetivo de apresentar à discussão alguns dos princípios e diretrizes que deveriam nortear uma Reforma Universitária capaz de promover as mudanças que o país precisa para continuar sua trajetória de afirmação no cenário global como um país que orienta suas políticas públicas na direção do desenvolvimento sustentável e da redução das desigualdades sociais, com respeito à diversidade e identidades regionais e compromisso com a melhoria das condições de vida de toda a população.

É imperativo que uma reforma da Educação Superior no Brasil tenha as balizas do estado democrático que vem sendo construído pelos governos e pela sociedade contemporânea. Igualmente importante é que ela seja capaz de introduzir e sustentar a modernização das Instituições de Ensino Superior e de inspirar a concepção de um projeto para a Educação Superior Nacional que subsidie os ajustes certamente necessários no Plano $\mathrm{Na}$ cional de Educação vigente.

Seria portanto aconselhável que ela fosse antecedida pela análise precisa do Plano Nacional de Educação ${ }^{6}$ aprovado pelo Congresso Nacional para o período 2001/ 2010; pela avaliação do processo de expansão ocorrido e pela revisão crítica dos programas de avaliação a que foi submetida a educação superior brasileira na última década.

É imprescindível que a Reforma enfrente com sucesso três desafios fundamentais: a modernização do sistema, o efetivo aprimoramento da qualidade da educação brasileira em todos os níveis, graus e modalidades e a democratização do ensino promovendo a inclusão social.

A divisa desta Reforma deve ser, sem dúvida, qualidade - modernização - in-

6 Lei $n^{\circ} .10 .172$, de 9 de janeiro de 2001. 
clusão social. Dentro desta perspectiva a Reforma necessária deve ser alicerçada nos seguintes princípios e diretrizes:

- normatizar a avaliação e a regulação;

- consolidar a autonomia universitária plena em todo o sistema;

- aplicar adequadamente o princípio da indissociabilidade do ensino, pesquisa e extensão;

- contemplar a diversidade de modelos de IES, programas, modalidades;

- promover a aplicação de novas tecnologias;

- estabelecer condições, incentivos e propostas para articulação e integração com a educação básica;

- ordenar o processo de expansão da educação superior;

- definir novos mecanismos de financiamento;

- redefinir as funções do MEC, CAPES, SESU, CNE, INEP;

- respeitar a Constituição Brasileira e o novo Código Civil.

\section{Avaliação e a Regulação}

A questão da avaliação do ensino superior brasileiro vem sendo discutida desde a apresentação das primeiras propostas pela Comissão Nacional de Reformulação do Ensino Superior criada pelo governo federal em 1985 e encontra parceiros em países como Espanha, França e Reino Unido, entre outros. Ainda que com metodologias específicas, o objetivo das avaliações é a melhoria da qualidade de ensino.
No Brasil, a avaliação da qualidade centrou-se historicamente na auto-avaliação institucional, com a criação do PAIUB (Programa de Avaliação Institucional das Universidades Brasileiras) institucionalizado em 1993 pelo Ministério da Educação ${ }^{7}$ com a finalidade de incentivar a auto-avaliação das instituições. A proposta do PAIUB definia a auto-avaliação como etapa inicial de um processo, que em seguida se estenderia a todas as dimensões da instituição, completando-se com a avaliação externa.

Na avaliação externa a educação brasileira tem experimentado, nos últimos anos, diferentes processos de avaliação em larga escala. Apenas para situar, e sem a pretensão de enumerar todos os procedimentos disponíveis, são bem conhecidos: o SAEB - Sistema de Avaliação da Educação Bási$\mathrm{ca}^{8}$, que se propõe a fornecer dados que subsidiem a formulação de políticas educacionais, o Exame Nacional do Ensino Médio9 - ENEM -, aplicado a concluintes do ensino médio, e que na verdade configura muito mais um instrumento de autoavaliação relativa aos conteúdos e habilidades fundamentais da Escola Básica do que um sistema que mensura a qualidade do ensino e o Exame Nacional de Cursos $^{10}$ - ENC (Provão), concebido para avaliar os conhecimentos adquiridos pelos alunos em fase de conclusão da graduação ${ }^{11}$.

Esse último, muito combatido nos seus primórdios pelas conseqüências negativas que poderia desencadear, (das quais algumas se

7 Portaria SESu/MEC n. 130, de 14 de julho de 1993.

8 Criado em 1988 e aplicado a cada dois anos a partir de 1990.

9 Instituído pela Portaria MEC n. 438, de 28 de maio de 1998 e aplicado a partir desse ano.

10 Criado pela Lei $n^{\circ}$. 9131, de 24 de novembro de 1995, e implantado a partir de 1996

11 Trata-se, em todos os casos, de métodos que avaliam resultados e por isso prestam-se à identificação de deficiências, à análise de desempenho e podem subsidiar planos de melhorias da qualidade do ensino. É importante também destacar que, enquanto métodos de avaliação de resultados, não é indicada a sua utilização para classificação de instituições, uma vez não são concebidos para atender a essa finalidade. 
confirmaram e outras não), acabou por ter o mérito de, talvez, ter sido a única medida do Ministério que realmente provocou impacto no aprimoramento do desempenho das instituições de ensino superior do País.

Infelizmente, a maneira como foi divulgado pelo governo e alguns dos objetivos que se procurou atingir com a sua utilização tornaram discutível o significado de seus resultados e prejudicaram a sua credibilidade como instrumento real de aperfeiçoamento da educação brasileira. Esqueceu-se muitas vezes que o Provão não era a avaliação em si, mas, quando muito, um indicador, um parâmetro confiável integrado em um programa mais abrangente de avaliação ${ }^{12}$.

A avaliação externa da educação superior na década de 90, além do Provão, era fundamentada no Censo Educacional e na Análise das Condições de Ensino. Quanto à avaliação das Condições de Ensino, destinada a examinar a organização pedagógica dos cursos e os recursos humanos e materiais existentes, para fins de autorização de funcionamento de cursos e de credenciamento de instituições, revelou-se tarefa extremamente trabalhosa, cara, de difícil padronização e com resultados questionáveis.

A experiência acumulada, resultante da aplicação nas instituições de ensino superior desses diversos procedimentos de avaliação, evidencia a necessidade de aprimorá-los, torná-los mais transparentes e democráticos. Não podem ser repetidos os equívocos do passado recente que dificultam a construção de uma avaliação que leve em conta a diversidade regional, as peculiaridades, as características e a missão das Instituições de Ensino Superior.
Muito recentemente, em um esforço para integrar organicamente os diferentes instrumentos de avaliação e superar as dificuldades já identificadas, foi instituído o Sistema Nacional de Avaliação da Educação Superior - SINA$\mathrm{ES}^{13}$ - que se encontra em fase inicial de implantação, sem que nenhuma instituição tenha sido avaliada segundo seus critérios. Portanto é muito provável que o modelo de avaliação proposto pelo SINAES venha a experimentar adaptações, alterações e aperfeiçoamento ao longo de sua futura implantação. Em conseqüência, seria desarrazoado procurar vincular a classificação das atuais instituições de ensino superior a resultados de suas avaliações nos termos do SINAES, como é preconizado pelo anteprojeto de reforma apresentado pelo Ministério da Educação ${ }^{14}$.

Um efetivo projeto de reforma da educação superior deve prever e integrar um sistema de avaliação abrangente isento e equânime no tratamento dos diferentes segmentos e instituições concernidos. Entendido exclusivamente como mecanismo de monitoramento e caução da qualidade e como instrumento orientador de gestão acadêmico-administrativa; deve estar orientado para a identificação dos pontos positivos e das fragilidades institucionais e ser capaz de oferecer caminhos para a correção de rumos ${ }^{15}$. Entendida e realizada como acompanhamento crítico da trajetória institucional em todas as suas dimensões, como mensuração criteriosa do desempenho efetivo e do grau de sua adequação os planos de desenvolvimento estabelecidos, como diagnóstico do real cumprimento da missão que a instituição assume, a avaliação externa se configura como uma le-

12 Face às resistências e oposições enfrentadas, o Exame Nacional de Cursos foi extinto em 2003, no primeiro ano do governo do Partido dos Trabalhadores, após a realização de sua oitava edição.

13 Lei $n^{\circ} .10 .861$, de 14 de abril de 2004.

14 art. 11 e 12.

15 Conforme prescreve a Lei de Diretrizes e Bases da Educação Nacional (BRASIL, 1996), em seu art. 46. 
gítima tarefa de órgãos de Estado, e como instrumento privilegiado de promoção do nível de qualidade dos serviços educacionais oferecidos pelo sistema.

Nessa perspectiva o sistema nacional de avaliação institucional não deve ser confundido nem aproximado, seja do ponto de vista de sua conceituação, seja do ponto de vista de sua execução, do conjunto de normas e ações voltadas para a regulação do sistema de educação superior. A regulação, que sem a menor dúvida deve considerar e aproveitar os resultados globais dos processos avaliativos, supõe a explicitação de políticas públicas relativas à expansão do ensino superior, às finalidades da educação superior (mero atendimento de demandas de mercado ou preparação de recursos humanos para a pesquisa, a inovação e o desenvolvimento sustentável), a previsão de metas qualitativas e quantitativas em planos de curto, médio e longo prazos.

Em que pese a publicação de uma série de normas legais que em princípio prestamse a configurar marcos regulatórios, será necessário o estabelecer mecanismos e estruturas, bem como definir, nas diferentes instâncias de governo, a quem cabe a responsabilidade da regulação para que ela possa ser percebida como processo diferenciado, essencial para a consolidação de uma políitica educacional. Até a presente data, em termos práticos, as funções e atribuições do SINAES, CONAES, INEP e SESu se confundem no processo Avaliação/Regulação.

\section{Autonomia}

Consagrando um princípio há muito presente na legislação educacional brasileira ${ }^{16}$, a Constituição Federal em seu artigo 207 estabelece que "As Universidades gozam de autonomia didático-científica, administrativa e de gestão financeira e patrimonial [...]", preceito que é explicitado e detalhado pelos artigos 53 e 54 da LDB (BRASIL, 1996).

As diferenças regionais do país, nos aspectos sociais, econômicos, culturais e educacionais e a diversidade das instituições de ensino superior, sejam públicas ou privadas, derivada de suas vocações, de seus objetivos e de seu empenho em refletir e atender às peculiaridades de sua área de influência implicam na adoção daquele postulado constitucional pelo sistema como um todo.

Em que pese o caráter mandatório do preceito constitucional, bem como a fundamentação factual da pertinência do princípio, a autonomia do ente universitário ainda não teve plena aplicação. Em primeiro lugar, e de modo geral, em razão de a legislação infraconstitucional, relativa à educação superior nacional, tender historicamente a regulamentar minuciosamente o funcionamento acadêmico e administrativo das instituições universitárias, tornando letra morta o dispositivo legal da autonomia ${ }^{17}$. Em segundo lugar, e especificamente em relação às instituições públicas, pelo fato de nunca terem sido definidas e implementadas as medidas legais e orçamentárias destinadas a garantir a sua

16 Vide Dec.n 19.851, de 11 de abril de 1931 (art. 90); Lei n. 4.024, de 20 de dezembro de 1961, (art. 80); Lei n 5.540 , de 28 de novembro de 1968, (art. 30).

17 A esse respeito a primeira versão pública do Anteprojeto de Reforma da Educação Superior do atual governo constitui exemplo típico da atuação do legislador educacional. Ao mesmo tempo em que reafirma o princípio da autonomia em seu art.15, ("autonomia universitária compreende a autonomia didático-científica, administrativa e de gestão financeira e patrimonial."), o nega ou restringe seja no aspecto administrativo, (art. 39, 73 e 74, que dispõem sobre a forma de escolha de dirigentes; art. 20 e 72, que dispõem sobre a natureza e composição de órgãos colegiados), seja no aspecto didático-científico, (art. 21 , 22, 23 e 24 que regulam a organização dos cursos de graduação; art. $8^{\circ}$, que se propõem definir os campos de saber a serem abrangidos pelas instituições de ensino superior). 
autonomia financeira $^{18}$, o que vem afetando seriamente a gestão das instituições públicas, em particular as Universidades Federais. Em terceiro lugar, e especificamente em relação às instituições particulares, a autonomia didático-científica é de fato extremamente relativa vez que, por um lado, não se pode desconsiderar que há instituições onde a autonomia é prerrogativa da mantenedora e não das instâncias intra-institucionais; por outro, não é possível negar nem minimizar a interferência abusiva do MEC sobre a organização e o funcionamento dessas instituições.

A autonomia acadêmica, administrativa, financeira e patrimonial da Universidade é essencial para a sua definitiva inserção no contexto em que se situa. E nos dias de hoje, face aos problemas acima mencionados, não se pode distinguir ou priorizar uma ou outra de suas vertentes. Isso porque a autonomia requer gestão compartilhada, pautada na definição de prioridades e isto quer dizer que a Universidade se torna completamente responsável pelas suas ações: interna e externamente, a ela cabe responder pelas iniciativas que desenvolve, pela direção que imprime ao seu desenvolvimento e por quem ou ao que especificamente busca atender. Cabe também a ela responder pela adequação e efetividade dos meios que definiu para utilizar o dinheiro público e prestar contas à sociedade e aos órgãos de governo que analisam a legalidade e a pertinência das ações que orientaram a sua utilização. Isso porque a autonomia da Universidade não a torna soberana. Se o preceito constitucional estabelece que as Universidades gozam de plena autonomia a legisla- ção dele derivada, e nele apoiada, deixa claro a natureza e o sentido dessa autonomia: o cumprimento integral dos fins e dos objetivos assinalados à educação superior e ao ente "universidade" em particular. Assim sendo, autonomia e cumprimento da missão institucional são elementos que guardam entre si uma relação de interdependência na qual este fundamenta e legitima de fato a autonomia de direito com que a universidade baliza a sua ação. Assim torna-se compreensível e indiscutível a necessidade do escrutínio público das ações e atividades da instituição universitária, vez que a perseguição de seus fins e objetivos constitui um serviço público ${ }^{19}$.

Dotar a Universidade pública de autonomia plena significa conferir-lhe a responsabilidade completa pelo seu destino. Definir meios e estabelecer normas legais que garantam o exercício pleno e uniforme da autonomia em Universidades públicas e privadas significa conferir-lhes a responsabilidade de cumprir suas funções em consonância com a autonomia que lhes foi assegurada e estabelecer mecanismos de cobrança adequados. $E$ isto é essencial, urgente e irreversível.

Quanto ao sistema privado deve-se ter sempre presente que o artigo 209 da Constituição Federal (BRASIL, 1998) estabelece que "o ensino é livre à iniciativa privada" condicionando esse exercício a duas exigências: "cumprimento das normas gerais da educação nacional" e "autorização e avaliação de qualidade pelo poder público". Portanto, da mesma forma que autonomia não pode ser confundida com so-

18 Única e solitária exceção neste cenário é a representada pelas universidades paulistas que têm autonomia financeira assegurada por lei desde 1989.

19 "Podemos assim afirmar que a Universidade goza de autonomia para executar essas atividades que lhes são próprias, e que não são realizadas para seu exclusivo interesse, mas constituem um serviço que presta à sociedade. Como conseqüência, o reconhecimento da autonomia não exime as instâncias públicas mais amplas da verificação da prestação efetiva destes serviços " (DURHAM, 2003, p. 276). 
berania é preciso ter presente que as Instituições de Ensino Superior Privadas não são concessionárias ou permissionárias, mas exercem as suas atividades amparadas pela Constituição Federal.

\section{Indissociabilidade do Ensino, Pesquisa e Extensão}

Em decorrência de sua inclusão no texto constitucional, o princípio da indissociabilidade entre ensino, pesquisa e extensão, foi rapidamente incorporado aos estatutos e regimentos das instituições de ensino superior. ${ }^{20}$

Entretanto, o reconhecimento protocolar da importância desse preceito legal e a sua inclusão formal nos documentos básicos de organização das instituições não têm gerado efeitos no cotidiano acadêmico ou alterado substantivamente as práticas educacionais.

Isto se deve a várias razões, principalmente a um entendimento inadequado do conceito de indissociabilidade, presente inclusive nos textos legais.

sistema federal de educação superior, estabelecido a partir da Lei de Diretrizes e Bases da Educação Nacional foi regulamentado por sucessivos decretos a partir de $1997^{21}$. O decreto 3860, ainda parcialmente prevalecente, estabelece em seu art. $8^{0}$ que "As universidades caracterizam-se pela oferta regular de atividades de ensino, de pesquisa e de extensão".
Conforme se pode depreender de imediato o texto legal interpreta de forma muito peculiar o conceito de indissociabilidade ao dar-lhe uma definição operacional: asseguram para si a condição de universidade aquelas instituições que desenvolvem atividades de ensino e atividades de pesquisa e atividades de extensão. É essa presença regular de três tipos de atividades que garante o status de universidade. Isso se torna ainda mais claro quando se atenta para as disposições legais ${ }^{22}$ que tratam do credenciamento de instituições universitárias. De acordo com essas disposições o princípio da indissociabilidade dissolve-se na apuração meramente quantitativa dos resultados das atividades educacionais desenvolvidas, (ensino mais pesquisa mais extensão).

Dessa forma, a avaliação do grau de cumprimento da disposição constitucional reduz-se a uma simples apuração da quantidade de projetos implementados na área da extensão e prestação de serviços, na identificação dos programas de pesquisa e/ou dos cursos de pós-graduação ${ }^{23}$ implantados e do nível de qualidade do ensino de graduação ministrado.

A legislação acima mencionada, em rigorosa observância do texto constitucional, limita a aplicação do princípio da indissociabilidade aos entes universitários. Não é aplicável, por exemplo, ao Centro Universitário, figura inovadora no conjunto das instituições

20 A respeito, ver Mazzili (1996).

21 Dec. n. 2.207, de 15 de abril de 1997; Dec. n. 2. 306, de 20 de agosto de 1997; Dec. 3.860, de 09 de julho de 2001; Dec. $n^{\circ}$. 5.225, de 1 de outubro de 2004.

22 Especialmente Portaria MEC n ${ }^{\circ}$ 637, de 3 de maio de 1997, e Resolução n0 2, de 7 de abril de 1998, da Câmara de Ensino Superior do Conselho Nacional de Educação (CNE/CES).

23 Simples identificação porque, quanto aos projetos, não há critérios claros e sistemáticos para apuração de sua qualidade e/ ou relevância, e, quanto aos cursos, prevalecem as avaliações realizadas por outra agência. 
de ensino superior brasileiras, que é definido como instituição de ensino pluricurricular que se caracteriza pela excelência do ensino oferecido, pela qualificação do seu corpo docente e pelas condições de trabalho acadêmico oferecidas à comunidade escolar ${ }^{24}$.

Porém, em 2003, a concepção e a aplicação legal do princípio da indissociabilidade são radicalmente alteradas com a edição do Decreto $n^{\circ} .4 .914$ que exige dos Centros Universitários, ao mesmo tempo o cumprimento dos requisitos constantes do art. 52 da Lei de Diretrizes e Bases ${ }^{25}$ e o atendimento do princípio da indissociabilidade entre ensino, pesquisa e extensão. A passividade e a indiferença com as quais esse decreto foi recebido pelas instituições por ele concernidas, pelas entidades mantenedoras e pelas suas organizações representativas constituem-se em um indício da ausência de uma noção clara a respeito desse princípio entre os agentes integrantes do sistema nacional de ensino superior.

resultado final, em decorrência das diferenças entre o texto constitucional, a LDB e a legislação que a regulamenta, ao que se acrescenta todas as implicações decorrentes do entendimento e do comportamento das Comissões de Especialistas responsáveis pela avaliação dos pedidos de autorização, reconhecimento ou renovação de reconhecimento de cursos ou de credenciamento e recredenciamento de instituições, é a transformação do princípio da indissociabilidade em um slogan ao qual estatutos e regimentos rendem homenagem ao incluírem, com todas as letras, o incentivo e o desenvolvimento da pesquisa e da extensão entre as finalidades e objetivos institucionais, independentemente da natureza administrativa da unidade educacional.

Em lugar de uma simples ou mesmo simplória reafirmação desse princípio, o projeto de uma autêntica reforma universitária deve explicitar que ele é na verdade um conceito, que não se reduz ao processo de produção de novos conhecimentos ou à realização de atividades para solucionar problemas sociais. Assim entendido, requer abordagem interdisciplinar, diálogo interinstitucional, organização curricular que contemple conteúdos básicos da área de conhecimento relacionada à formação profissional e que acolha a contribuição de ciências conexas. Enquanto conceito, ele requer o desenvolvimento de atitudes em relação ao desenvolvimento científico, às transformações advindas da tecnologia e aos rumos da sociedade contemporânea.

Assim poderá o princípio, incluído nos estatutos e regimentos de todas as IES independentemente do seu modelo de organização, ser um instrumento efetivo a orientar a estruturação de suas práticas pedagógicas e a organizar a imbricação, a inter-relação e a sinergia do ensino, da pesquisa e da extensão.

24 Decreto n 2.207/97, art. 60; Decreto n².306/97, art. 12 e Decreto n 3.860/01. art. 11. Deve-se observar que há uma profunda diferença de concepção entre a caracterização de Centro Universitário presente nestes três decretos e aquela que é explicitada na Portaria Ministerial 2041, de 22 de outubro de 1997: "Os Centros Universitários são instituições que se caracterizam: quanto à abrangência, por organização pluricurricular em uma ou mais áreas de conhecimento ou de formação profissional, nos níveis de graduação, extensão e especialização; [...] quanto à função, pela excelência do ensino ministrado, pelas modalidades de aperfeiçoamento permanente do ensino de graduação, pela qualificação constante de seu corpo docente, pela oferta de cursos de graduação, extensão, especialização e seqüenciais, e pelas atividades integradas de pesquisa discente.

25 São eles: I - produção intelectual institucionalizada mediante o estudo sistemático dos temas e problemas mais relevantes, tanto do ponto de vista científico e cultural, quanto regional e nacional; II - um terço do corpo docente, pelo menos, com titulação acadêmica de mestrado ou doutorado; III - um terço do corpo docente em regime de tempo integral. (BRASIL, 1996). 
Deve, pois, ser ressaltado que instituições de ensino superior podem - como inúmeras de fato o fazem - desenvolver senviços educacionais relevantes e de qualidade sem exibir pesquisa institucionalizada e quadros de pesquisadores ativos. Exigir, em nome de um entendimento pedestre do princípio da indissociabilidade, que toda e qualquer instituição de ensino superior demonstre a existência, ao lado de um ensino de qualidade, de programas estruturados e diversificados de extensão, e de pesquisa institucionalizada é, mais do que um equívoco, uma insensatez. Em um país como o Brasil, marcado por diversidades regionais, por desigualdades de recursos humanos e materiais entre as Instituições e por uma crônica escassez de fontes de financiamento é indiscutível que as condições mínimas ${ }^{26}$ para a produção de conhecimento pela pesquisa de qualidade são encontráveis, quando muito, em 10\% das Instituições de Ensino Superior, aí incluídas as Públicas.

\section{Diversificação de Modelos de Instituições, de Programas e Modalidades de Ensino}

A história da educação superior brasileira é uma história de modelo único, no qual as instituições de ensino quer fossem públicas ou privadas, universitárias ou simples faculdades isoladas, deveriam de acordo com o ideário do MEC e a legislação educacional seguir e serem avaliadas pelo prisma do modelo ideal das Universidades Federais. Essa situação, irreal e distante das necessidades do país foi parcialmente modificada pela Lei de Diretrizes e Bases da Educação que inovou criando as Universidades por campo do saber, os Centros Universitários, o Instituto Normal Superior, os cursos de curta duração e outros programas de menor impacto.
Nessa mesma direção, e com ênfase ainda maior, documentos da UNESCO e do Banco Mundial, assimilados pela Academia e Governos dos países mais desenvolvidos, demonstram de forma inequívoca que o avanço do conhecimento e a de formação de recursos humanos qualificados para fazer frente aos desafios da era do conhecimento só poderá ser atendido por meio da diversificação, da flexibilização de modelos de ensino e de instituições e da implantação de programas de formação profissional não convencionais, de qualidade e em consonância com as necessidades da sociedade. Portanto, uma reforma para fazer avançar e para aperfeiçoar o Sistema Educacional Brasileiro não pode continuar vinculada à idéia de um modelo úni$\mathrm{co}$, nem atribuir direitos de precedência ao ente universidade. Pelo contrário, deve prever e promover, inclusive com a definição de medidas concretas, a implantação de instituições e programas de ensino que, por suas missões e seus objetivos, possam enfrentar o desafio representado pelas múltiplas e cambiantes formações exigidas pela sociedade e pela economia do conhecimento.

\section{Aplicação de Novas Tecnologias em Educação}

A atual conjuntura mundial não permite que uma Reforma Universitária para o Século XXI deixe de abordar o emprego de novas tecnologias em educação. É crescente o emprego da educação a distância da robótica e da telemática e de softwares inovadores e de grande utilidade no processo ensino aprendizagem.

26 Massa crítica de pesquisadores qualificados, tradição, laboratórios modernos e bem equipados, bibliotecas atualizadas e recursos financeiros suficientes para custeio e investimento. 
É inquietante que na primeira versão do anteprojeto da Reforma Universitária apresentado pelo MEC a Educação a Distância não tivesse sido abordada. Essa modalidade cresce de forma impressionante no Brasil: um grande número de IES tem sido credenciado para a oferta de educação na modalidade a distância; o número de vagas abertas chega a ser assustador, tornando imprescindível um marco regulatório e um processo de avaliação que garanta a qualidade dos cursos ofertados e a credibilidade do sistema.

\section{Articulação e Integração com a Educação Básica}

Cristóvam Buarque (2005, p. 3), Senador da República e ex-Ministro da Educação do atual governo, entende que:

Enquanto a educação básica não for reformada, a universidade não terá qualidade total. Com apenas 1/3 de jovens concluindo o ensino médio, estamos desperdiçando o potencial de milhões de cérebros. Com um ensino médio sem qualidade, condenamos a universidade a receber jovens ainda não preparados. $O$ bom desempenho das universidades de outros países não acontece porque eles são mais inteligentes, mas sim porque têm a probabilidade maior de ter bons alunos, pois é possivel escolher entre todos e não apenas entre poucos de seus jovens.

A leitura do texto remete de pronto à convicção de que não será possível esperar que o ensino médio ganhe qualidade para reformar a educação superior.

As instituições de ensino superior, pelos recursos humanos de que dispõem e pelo estoque de competências e de conhecimentos que detêm, exercem papel de destaque na proposição de projetos, ações e iniciativas voltadas para o equacionamento e solução dos problemas nacionais. Desta forma, devem assumir a liderança na cooperação com os sistemas de educação básica de modo a efetivamente contribuir para a melhoria da qualidade da escola básica. A mais importante tarefa que deve ser cumprida pelas instituições de ensino superior é a formação de professores, mediante a organização das licenciaturas e a implantação de programas de educação continuada. Nesse fazer, há que lançar mão de meios e tecnologias que facilitem e valorizem a aproximação entre o professor de ensino fundamental e a instituição de ensino superior. $A$ capacitação do professor constitui-se como um eixo articulador de outras atividades também importantes, como a preparação de material pedagógico e a capacitação de gestores para a escola básica.

Um projeto de Reforma Universitária precisa situar a relação Universidade-Escola Básica num plano mais abrangente e duradouro, que garanta a articulação entre os diferentes níveis de ensino na promoção da qualidade da educação. A melhoria da qualidade da educação básica é o mecanismo mais adequado para a democratização do acesso à educação superior.

\section{Expansão do Ensino Superior}

O processo de expansão da Educação Superior nas duas últimas décadas foi permeado por inúmeros problemas referentes, sobretudo, à inexistência de planejamento, à qualidade do ensino ofertado, ao atendimento desequilibrado das áreas do conhe- 
cimento e das regiões brasileiras o que torna legítimo questionar a sua eficácia. Não é, portanto, de se estranhar o fato de uma oferta tão significativa não ter sido capaz de ampliar o percentual de jovens brasileiros que estão adequando formação superior de modo a alcançar o patamar de outros países latino-americanos. De fato em 2005, enquanto Argentina, Uruguai, Bolívia e México têm, respectivamente, 48, 34, 33 e $20 \%$ de jovens entre 18 e 24 anos freqüentando o ensino superior, o percentual brasileiro mal chega a $15 \%$.

É imprescindível ordenar a expansão do ensino superior com o objetivo de: aumentar as vagas no sistema público, tornando a relação entre as vagas ofertadas pelos sistemas público e privado mais equilibrada; diminuir as diferenças regionais atualmente existentes; adequar a oferta de vagas nas diferentes áreas do conhecimento às necessidades da sociedade e ao projeto de desenvolvimento do País; incentivar a expansão da educação tecnológica; ampliar a oferta de cursos de curta duração; desenvolver a educação a distância.

Entretanto, essa expansão deve ser feita após a avaliação: da expansão exponencial realizada nos últimos dez anos; das muitas do Plano Nacional de Educação (aprovada pelo Congresso Nacional) e da consolidação do Sistema Nacional de Avaliação do Ensino Superior (SINAES).

A adoção de mecanismos de funcionamento mais apropriados, a autonomia das Universidades Federais com a prometida elevação de recursos financeiros para o sistema público e a reformulação do Programa Universidade para Todos - PROUNI, são medidas necessárias para promover a expansão da educação superior dentro de padrões de qualidade. No caso do PROU$\mathrm{NI}$ só deveriam participar do programa instituições que apresentassem desempenho satisfatório na avaliação institucional a cargo do CONAES e baseada no ENADE e na avaliação das condições de ensino executadas pelo INEP.

\section{Financiamento}

financiamento é um dos elementos essenciais para definir e implantar políticas públicas, e essa condição se explica pela sua relação direta com os limites e a qualidade dos serviços a serem oferecidos.

A Constituição Federal determina que compete à União a manutenção de suas instituições de ensino superior, enquanto estados e municípios devem responder pela oferta da educação básica. Dados relativos a $1999^{27}$ mostram que o investimento do Estado brasileiro em educação equivale a $4,3 \%$ do Produto Interno Bruto (PIB), e que à educação superior corresponde $0,9 \%$ do $\mathrm{PIB}^{28}$; do volume total de recursos aplicados na educação superior a União responde por aproximadamente dois terços, (65,7\%). De acordo com dados do Ministério da Fazenda os recursos da União destinados ao financiamento do ensino superior atingem as cifras de 5.751,9 e de 6306,0 milhões de reais em 2001 e 2002, correspondentes, respectivamente, a $53,8 \%$ e $56,3 \%$ do total de gastos federais com a área da Educação (BRASIL, 2005).

27 INSTITUTO NACIONAL DE ESTUDOS E PESQUISAS EDUCACIONAIS ANÍSIO TEIXEIRA, [199-?].

28 Isso equivale ao dispêndio de $R \$ 41.476 .976 .000,00$ com a educação como um todo e de $R \$ 8.846 .036 .000,00 \mathrm{com}$ o ensino superior. 
Nos últimos anos, especialmente na área federal, esses recursos têm-se mostrado insuficientes para financiar as atividades das instituições públicas que passaram a enfrentar séria crise de sustentabilidade ${ }^{29}$, que atinge desde a manutenção das suas instalações, passa pela renovação de quadros de pessoal e torna inviável qualquer projeto significativo de assistência financeira ao estudante carente. Esse último aspecto afeta também o sistema privado que, por concentrar um alto percentual de cursos noturnos, tem dado conta da oferta de formação superior a estudantes trabalhadores os quais, por força das flutuações do mercado de trabaIho, tornam-se inadimplentes afetando a arrecadação das entidades mantenedoras.

Diante desse quadro é imprescindível que uma reforma da educação superior compreenda a elaboração de nova equação para o financiamento da educação superior, que contemple a revisão de percentuais destinados à educação superior ${ }^{30}$, garanta a autonomia de gestão financeira do sistema público federal e que defina mecanismos adicionais de financiamento estudantil que possibilitem não somente 0 ingresso, mas, sobretudo, a permanência e a conclusão dos estudos superiores ao aluno carente, seja em instituições públicas seja em instituições privadas.

A autonomia de gestão financeira tem modelos nacionais: implantada desde 1989 nas universidades estaduais paulistas tem permitido a racionalização de recursos, a formulação de políticas salariais duradouras, a modernização da infra-estrutura e a expansão qualificada da oferta de ensino. Essa experiência, bem conhecida, inclusive no que concerne aos ajustes ainda necessários, pode ser útil para montar a equação dos financiamentos das IFES.

Embora não seja condição suficiente para solucionar todos os problemas de sustentabilidade das instituições federais de ensino superior, a autonomia financeira dessas instituições e a conseqüente responsabilidade da gestão, com a aplicação de critérios públicos e transparentes, permite uma visão correta e completa das demandas para as quais é preciso buscar fontes alternativas de financiamento.

\section{Redefinição das Funções do MEC, CAPES, SESU, CNE, INEP.}

A dimensão do sistema nacional de ensino superior e a complexidade das tarefas de avaliar, credenciar, reconhecer, renovar créditos, formalizar procedimentos, analisar, emitir laudos e preparar relatórios requer uma revisão das estruturas centrais de coordenação, apoio e processamento técnico dessas atividades. Isso é natural, pois deve acompanhar a evolução do sistema para que o padrão de eficiência, a pontualidade e o rigor técnico possam acompanhar a evolução tecnológica como vem acontecendo.

29 Especialmente pela ação combinada de dois fatores: o primeiro, o ônus representado pela inclusão das aposentadorias e pensões nas despesas de pessoal das instituições universitárias; o segundo, a redução, em termos relativos, do montante de gastos governamentais com o ensino superior.

30 Para essa questão há uma proposta muito interessante na contribuição apresentada pela Associação Nacional dos Dirigentes das Instituições Federais de Ensino Superior. Ela consiste essencialmente em adotar a "receita bruta do Tesouro", e não mais a "receita de impostos" como base de cálculo dos recursos constitucionalmente vinculados à manutenção e desenvolvimento do ensino, e destinar $50 \%$ do assim apurado para o ensino superior (ASSOCIAÇÃO NACIONAL DOS DIRIGENTES DAS INSTITUIÇÕES FEDERAIS DE ENSINO SUPERIOR, 2005). 
É imprescindível, pois, redefinir as funções dos órgãos federais da Educação Superior, tendo como base uma diretriz que resulta da própria complexidade que o sistema hoje exibe: trata-se de orientar a revisão de responsabilidades de modo a evitar a sobreposição de atribuições que acabam por levar a uma excessiva centralização do poder, incompatível com a maturidade democrática que o Brasil já alcançou. Avaliação, Supervisão e Regulação devem ser responsabilidades de áreas independentes e isso indica a necessidade de criação de uma agência oficial de Avaliação da Educação Superior, inclusive da pós-graduação, evitando que a CAPES continue com os encargos de avaliar, credenciar e financiar a formação avançada. Da mesma forma, deverá o CNE assumir a sua real condição de órgão de Estado, formulador de políticas educacionais e instância recursal. Ao MEC caberá a missão de regulação e supervisão do sistema de educação superior, transferidas as atribuições ligadas ao financiamento do sistema federal, na esteira da autonomia financeira, a um órgão composto predominantemente por membros das universidades e instituições de ensino não universitárias federais.

\section{Aspectos Jurídicos}

A Reforma Universitária pretendida não deve em hipótese alguma afrontar a Constituição Federal, a legislação educacional infraconstitucional vigente e o recém aprovado Código Civil. Portanto, na proposta definitiva do Governo deve ser modificada a redação do anteprojeto, na sua versão primeira, a qual apresenta 100 artigos englobando pontos fundamentais da educação brasileira dos quais cerca de 30 apresentam manifesta inconstitucionalidade.
Em análise propositiva, e dentre as inovações positivas e de consenso no âmbito das IES públicas, importante citar a proposta de autonomia financeira e patrimonial e a determinação da forma de financiamento para as Instituições Federais de Ensino Superior e, como negativa ou controvertida, a eleição de dirigentes máximos, reitor e vice-reitor, mediante eleição direta da comunidade acadêmica, em detrimento do mérito Acadêmico.

Contudo, no tocante às IES privadas, a situação apresenta-se mais complexa: as alterações pretendidas pelos diversos dispositivos espraiados ao longo do texto do Anteprojeto, com maior ou menor intensidade, violam os preceitos constitucionais da livre iniciativa (art. $1^{\circ}$ combinado com o art. 170 §único, da C.F.) e da autonomia universitária (arts. 207 e 209, da C.F.), revelando-se, por corolário, como ingerência inconstitucional na seara da iniciativa privada.

Dessarte, em que pese a oportunidade da discussão, cabe alertar para impedimento de ordem Constitucional indelével que, ao que parece, vem sendo tratado como obstáculo contornável pelos representantes do Ministério da Educação, conforme se depreende de entrevistas veiculadas perante a mídia e diante do texto do projeto apresentado.

Ou seja, o que se quer afirmar é que há um conflito conceitual entre a norma proposta (em seu conteúdo axiológico) com os valores logrados pela República, mormente diante da formulação normativa (o texto de lei) efetivamente apresentada; não olvidando ainda que as Constituições, ao contrário das Leis, têm sua hermenêutica fulcrada na maior efetividade de seus dispositivos, evitando-se interpretações que restrinjam o alcance integral de seus dispositivos, mormente quando não previsto. 
Assim, não obstante as declarações públicas dignificantes do MEC com relação aos objetivos pretendidos pela Reforma - sob o pálio de corrigir eventuais distorções verificadas no mercado de ensino privado; de introduzir mecanismos democráticos de gestão etc - ressalte-se que o texto apresentado viola um dos fundamentos da República (art. $1^{\circ}$, IV da Constituição Federal), assentado pela Assembléia Constituinte Originária de 1988, que optou por uma Carta Magna fundada no liberalismo econômico, no primado do trabalho e da livre iniciativa.

Assim, a regulamentação do Ensino Superior, na formulação normativa apresentada pelo texto do Anteprojeto não pode prosperar, do azo que, além de cercear a autonomia universitária em maior ou menor grau, conforme se depreende de vários dispositivos, atenta contra um dos pilares que sustentam a República (a livre iniciativa); valor que a sociedade entende que deve ser preservado.

Em tempo, temos que o MEC deverá promover a autocrítica e resignar-se, no texto definitivo, aos limites naturais impostos (de conteúdo e forma) à reforma de tex- to normativo em um Estado democrático de direito, seja qual for a orientação política do mandatário de época.

Diante deste descompasso jurídico, revela-se como melhor solução estender o debate, sopesar as propostas, esclarecer os pontos divergentes, avançar com relação aos convergentes e, sobretudo, exercer trabalho reflexivo exaustivo, livre das amarras ideológicas e político-partidárias, para finalmente apresentar um projeto de lei sem qualquer açodamento, respeitando-se os fundamentos da República (em especial, art. $1^{0}$, inciso IV), a segurança jurídica (art. $5^{\circ}$ incisos XXVI, CF.) das relações jurídico-institucionais já constituídas, e as que se constituirão, a fim de proporcionar a mansa implantação das inovações legais de forma perene e continuada, evitando-se contestações judiciais que certamente macularão a credibilidade do anteprojeto de reforma universitária em curso.

Afinal, os homens têm seus propósitos ligados a sua condição humana, de existência temporal finita; as Instituições são organizações sociais criadas para que o incremento de seus desideratos perdure virtuosamente e ao longo do tempo. 


\section{Referências}

\section{ASSOCIAÇÃO NACIONAL DOS DIRIGENTES DAS INSTITUIÇÕES FEDERAIS DE}

ENSINO SUPERIOR. Anteprojeto de lei da reforma da educação superior: propostas de emendas da Andifes. Revista, Brasília, DF, 30 mar. 2005.

Disponível em: <http//:www.andifes.org.br/files/revista.pdf>. Acesso em: 14 abr. 2005.

BRASIL. Constituição (1988). Constituição da República Federativa do Brasil: promulgada em 5 de outubro de 1988: acompanhada de disposições anteriores... 2. ed. São Paulo: Ed. Oliveira Mendes, 1998.

Decreto $\mathrm{n}^{\circ}$ 2.207, de 15 de abril de 1997. Regulamenta para o Sistema Federal de Ensino, as disposições contidas nos arts. 19,20,45, 46 e $\S 1^{\circ}, 52$, parágrafo único, 54 e 88 da Lei $n^{\circ}$ 9.394, de 20 de dezembro de 1996, e dá outras providências. Diário Oficial [da] República Federativa do Brasil, Brasília, DF, 16 abr. 1997.

Disponível em: <http://www.planalto.gov.br/>. Acesso em: 22 jun. 2005.

Decreto $n^{\circ} 2.306$, de 19 de agosto de 1997. Regulamenta, para o Sistema Federal de Ensino, as disposições contidas no art. 10 da Medida Provisória $\mathrm{n}^{\circ} 1.477$ 39 , de 8 de agosto de 1997, e nos arts. 16, 19, 20, 45, 46 e $\S 1^{\circ}$, 52, parágrafo único, 54 e 88 da Lei n 9.394, de 20 de dezembro de 1996, e dá outras providências. Diário Oficial [da] República Federativa do Brasil, Brasília, DF, 20 ago. 1997.

Disponível em: <http://www.planalto.gov.br/>. Acesso em: 22 jun. 2005.

\section{Decreto $n^{\circ} 2.406$, de 27 de novembro de 1997. Regulamenta a Lei n 8.948,} de 8 de dezembro de 1994, e dá outras providências. Diário Oficial [da] República Federativa do Brasil, Brasília, DF, 28 nov. 1997.

Disponível em: <http://www.planalto.gov.br/>. Acesso em: 22 jun. 2005.

Decreto $\mathrm{n}^{\circ} 3.462$, de 17 de maio de 2000. Dá nova redação ao art. 80 do Decreto $n^{\circ}$ 2.406, de 27 de novembro de 1997, que regulamenta a Lei no 8.948, de 8 de dezembro de 1994. Diário Oficial [da] República Federativa do Brasil, Brasília, DF, 18 maio 2000.

Disponível em: <http://www.planalto.gov.br/>. Acesso em: 22 jun. 2005.

. Decreto $n^{\circ} 3.741$, de 31 de janeiro de 2001. Altera a redação do art. 5o do Decreto no 2.406, de 27 de novembro de 1997, que regulamenta a Lei o 8.948, de 8 de dezembro de 1994. Diário Oficial [da] República Federativa do Brasil, Brasília, DF, 1 fev. 2001. Disponível em: <http://www.planalto.gov.br/>. Acesso em: 22 jun. 2005.

Decreto $n^{\circ} 3.860$, de 9 de julho de 2001. Dispõe sobre a organização do ensino superior, a avaliação de cursos e instituições, e dá outras providências. Diário Oficial [da] República Federativa do Brasil, Brasília, DF, 10 set. 2001.

Disponível em: <http://www.planalto.gov.br/>. Acesso em: 22 jun. 2005. 
BRASIL. Decreto $n^{\circ} 4.914$, de 11 de dezembro de 2003. Dispõe sobre os centros universitários de que trata o art. 11 do Decreto no 3.860, de 9 de julho de 2001, e dá outras providências. Diário Oficial [da] República Federativa do Brasil, Brasília, DF, 12 dez. 2003. Edição extra.

Disponível em: <http://www.planalto.gov.br/>. Acesso em: 22 jun. 2005.

Decreto $n^{\circ} 5.224$, de $1^{\circ}$ de outubro de 2004. Dispõe sobre a organização dos Centros Federais de Educação Tecnológica e dá outras providências. Diário Oficial [da] República Federativa do Brasil, Brasília, DF, 4 out. 2004.

Disponível em: <http://www.planalto.gov.br/>. Acesso em: 22 jun. 2005.

Decreto $n^{\circ}$ 5.225, de 1 de outubro de 2004. Altera dispositivos do Decreto $\mathrm{n}^{\circ}$ $\overline{3.860}$, de 9 de julho de 2001, que dispõe sobre a organização do ensino superior e a avaliação de cursos e instituições, e dá outras providências. Diário Oficial [da] República Federativa do Brasil, Brasília, DF, 4 out. 2004.

Disponível em: <http://www.planalto.gov.br/>. Acesso em: 22 jun. 2005.

. Lei $n^{\circ}$ 4.024, de 20 de dezembro de 1961. Fixa as Diretrizes e Bases da Educação Nacional. Diário Oficial [da] República Federativa do Brasil, Brasília, DF, 27 dez. 1961 e retificada em 28 dez. 1961.

Disponível em: <http://www.planalto.gov.br/>. Acesso em: 22 jun. 2005.

. Lei $n^{\circ} 5.540$, de 28 de novembro de 1968. Fixa normas de organização e funcionamento do ensino superior e sua articulação com a escola média, e dá outras providências. Diário Oficial [da] República Federativa do Brasil, Brasília, DF, 29 nov. 1968 e retificada em 3 dez. 1968.

Disponível em: <http://www.planalto.gov.br/>. Acesso em: 22 jun. 2005.

. Lei $n^{\circ}$ 9.131, de 24 de novembro de 1995. Altera dispositivos da Lei $n^{\circ} 4.024$, de 20 de dezembro de 1961, e dá outras providências. Diário Oficial [da] República Federativa do Brasil, Brasília, DF, 25 nov. 1995 (Edição extra).

Disponível em: <http://www.planalto.gov.br/>. Acesso em: 22 jun. 2005.

. Lei n 9.394, de 20 de dezembro de 2001. Estabelece as diretrizes e bases da educação nacional. Diário Oficial [da] República Federativa do Brasil, Brasília, DF, 23 dez. 1996. Disponível em: <http://www.planalto.gov.br/>. Acesso em: 23 jun. 2005.

- Lei $n^{\circ} 10.172$, de 9 de janeiro de 2001. Aprova o Plano Nacional de Educação e dá outras providências. Diário Oficia [da] República Federativa do Brasil, Brasília, DF, 11 jan. 2001. Disponível em: <http://www.planalto.gov.br/>. Acesso em: 23 jun. 2005. 
BRASIL. Lei $n^{\circ}$ 10.861, de 14 de abril de 2004. Institui o Sistema Nacional de Avaliação da Educação Superior - SINAES e dá outras providências. Diário Oficial [da] República Federativa do Brasil, Brasília, DF, 15 abr. 2004.

Disponível em: <http://www.planalto.gov.br/>. Acesso em: 23 jun. 2005.

- Ministério da Educação. Anteprojeto da Lei de Educação Superior.

Disponível em: <http://portal.mec.gov.br/reforma/Documentos/anteprojeto.pdf $>$.

Acesso em: 19 abr. 2005.

- Ministério da Educação. Secretaria de Educação Superior. Portaria $n^{\circ} 130$, de 14 de julho de 1993. Cria Comissão com o objetivo de estabelecer diretrizes e viabilizar a implementação do processo de avaliação institucional nas universidades brasileiras. Prolei. Brasília, DF, 1993. Disponível em: < http://www.prolei.inep.gov.br/prolei>. Acesso em: 29 jun. 2005.

. Ministério da Educação. Secretaria de Educação Superior. Portaria $n^{\circ}$ 637, de 13 de maio de 1997. Dispõe sobre o credenciamento de universidades. Legislação, Brasília, DF, [1997?]. Disponível em <http://portal.mec.gov.br/sesu/arquivos/pdf/p637.pdf>. Acesso em: 23 jun. 2005.

- Ministério da Educação e do Desporto. Portaria $n^{\circ}$ 438, de 28 de maio de 1998. Institui o Exame Nacional do Ensino Médio - ENEM, como procedimento de avaliação do desempenho do aluno. Brasília, DF, 1998.

Disponível em:< http://www.abmes.org.br>. Acesso em: 29 jun. 2005.

- Ministério da Fazenda. Secretaria de Política Econômica. Gasto social do Governo Central 2001/2002. Brasília, DF, 2003.

Disponível em: <http://www.fazenda.gov.br >. Acesso em: 27 jun. 2005.

. Orçamento social do Governo Federal 2001/2004. Brasília, DF, 2005.

Disponível em: <http://www.fazenda.gov.br>. Acesso em: 27 jun. 2005.

BUARQUE, C. Reforma de conceito. Jornal do Commercio, Recife, p. 3, 4 mar. 2005.

CONSELHO NACIONAL DE EDUCAÇÃO (Brasil). Câmara de Educação Superior.

Resolução CES n 2, de 7 de abril de 1998. Estabelece indicadores para comprovar a produção intelectual institucionalizada, para fins de credenciamento, nos termos do Art. 46 do Art. 52, inciso I, da Lei 9.394/96, de 20 de dezembro de 1996. Legislação, Brasília, DF, [1998?].

Disponível em: <http://portal.mec.gov.br/cne/arquivos/pdf/CES0298.pdf>. Acesso em: 23 jun. 2005. 
INSTITUTO NACIONAL DE ESTUDOS E PESQUISAS EDUCACIONAIS ANÍSIO TEIXEIRA. Evolução da educação superior: graduação 1980-1998. Brasília, DF, [1998?]. Disponível em: <http://www.inep.gov.br/dowload/censo/1998/superior/evolucao_1980-1998.pdf >. Acesso em: 20 abr. 2005.

Gastos com educação. Brasília, DF, [199-?].

Disponível em: <http://www.inep.gov.br/estatisticas/gastoseducacao >.

Acesso em: 14 abr. 2005.

. Sinopses estatísticas do ensino superior: graduação 1997 a 2003. Brasília, DF, [2003?]. Disponível em: <http://www.inep.gov.br/superior/censosuperior/sinopse/ default.asp $>$. Acesso em: 20 abr. 2005.

MACEDO, A. R. Necessidade, oportunidade e mérito. Folha de S. Paulo, São Paulo, p. 3, 14 mar. 2005. abr. 2005.

papel social da universidade. Estudos, Brasília, DF, ano 23, n. 34, p. 7-12,

MAZZILI, S. Notas sobre indissociabilidade entre ensino-pesquisa-extensão. Universidade e Sociedade, Brasília, DF, v. 6, n. 11, p. 4-10, jun. 1996.

MORRHY, L. (Org.). Universidade em questão. Brasília, DF: Universidade de Brasília, 2003.

UNESCO. World education report 2000: the right to education. Paris, 2000. Disponível em: <http://www.unesco.org/education/information/wer/PDFeng/wholewer.PDF>. Acesso em: 18 abr. 2005.

Recebido em: 31/05/2005

Aceito para publicação em: 28/06/2005 